\title{
INTEREST SHOWN BY MEDICAL STUDENTS AT UNIVERSITY OF SAN PABLO CEU (SPAIN) REGARDING PREVENTION AND RESPONSE TO OUTBREAKS OF INFECTION
}

\author{
A. Peña-Fernández ${ }^{1}$, S. Fenoy ${ }^{2}$, M.C. Lobo-Bedmar ${ }^{3}$ \\ ${ }^{1}$ De Montfort University, Faculty of Health and Life Sciences (UNITED KINGDOM) \\ ${ }^{2}$ Universidad San Pablo CEU, Facultad de Farmacia (SPAIN) \\ ${ }^{3}$ IMIDRA, Departamento de Investigación Agroambiental (SPAIN)
}

\begin{abstract}
The release of biological hazards during biological incidents, bioterrorism or outbreaks of infection has shown to represent a significant challenge for healthcare professionals as it can involve significant numbers of patients and represent a global public health threat. Healthcare educators should provide students with the necessary skills in medical preparedness and response to these incidents to protect the public. However, this is not standardised in the medical curriculum. An innovative teaching group at De Montfort University (DMU, UK) in collaboration with first responders that worked during the 2014-2016 Ebola outbreak in a Public Health England (PHE) mobile laboratory in Sierra Leone, have developed different, novel teaching training sessions to provide health science students with the necessary skills to respond to these events. We have tested the training sessions with students from three different undergraduate (BSc Biomedical and Medical Science) and postgraduate (MSc Advanced Biomedical Science) human health programmes at DMU. In general, these sessions were shown to be successful in providing students with basic skills to respond to minor biological incidents (Peña-Fernández et al., 2017) [1], although we do not know if these could be adopted to develop standardized curricula across any human health degree in the European Union (EU). Therefore, the purpose of this work was twofold: a) to assess the effectiveness of the specialised training session that covers the medical response to protect public health with medical students; and b) to determine the effectiveness of the training session, initially developed in England, in a non-English EU university. To meet these objectives, we have simplified this specialised training and delivered it to final year students of the Medicine degree at the University of San Pablo CEU (USP-CEU, Spain) during an Eramus+ mobility grant for academics in April 2017. The two hour training provided consisted of developing a complete intervention programme to deal with an outbreak of Crimean-Congo haemorrhagic fever (CCFH) virus following the steps of evidence-based public health. CCFH is a haemorrhagic fever virus causing devastating disease symptoms that result in intense and prolonged suffering in humans and has become an increasing global health concern. This paper will describe the teaching resources used and a comprehensive analysis of students' feedback to this training. Briefly: the specific questionnaire used has shown high levels of engagement and satisfaction $[100 \%(31.2 \%$ agreed; $68.8 \%$ strongly agreed)] with the USP-CEU medical students. Despite its short duration, this training would be successful in providing medical students with the necessary skills to respond to a biological event. Thus, $100 \%$ (31.2\% agreed; $68.8 \%$ strongly agreed) of these students reported that they learnt how to establish some public health interventions to protect humans in the aftermath of an outbreak of infection. Moreover, all USP-CEU responders have described that they gained appropriate knowledge of public health prevention and preparedness against these events $(37.5 \%$ agreed; 62.5 strongly agreed). Finally, the Erasmus+ mobility grant for academics has been shown to be a relevant tool and resource to strengthen curricula development and validation in higher education.
\end{abstract}

Keywords: Curriculum development, medical preparedness training, evidence-based public health, Erasmus.

\section{INTRODUCTION}

Biological incidents and outbreaks of infection are natural, accidental or deliberate (bioterrorism) events that involve the release and spread of biological agents or hazards [2]. Biomedical scientists were critical for the response to the unprecedented 2014-16 Ebola crisis in West Africa, highlighting the relevance of teaching skills for response to biological incidents. However, time dedicated to studying these topics in the Biomedical Science degree at De Montfort University was minimal. As a consequence, an innovative teaching group at De Montfort University (DMU, UK) in collaboration with first responders that worked during the Ebola outbreak in a Public Health England (PHE) mobile 
laboratory in Sierra Leone, have developed different, novel teaching training sessions to provide health science students with the necessary skills to respond to these events [1,3-4].

We have tested the training sessions with students from three different undergraduate (BSc Biomedical and Medical Science) and postgraduate (MSc Advanced Biomedical Science) human health programmes at DMU. In general, these sessions were shown to be successful in providing students with basic skills to respond to minor biological incidents [1]) to assess the effectiveness of the specialised training session that covers the medical response to protect public health with medical students; and b) to determine the effectiveness of the training session, initially developed in England, in a non-English EU university.

\section{METHODOLOGY}

To meet these objectives, we have simplified this specialised training and delivered it to final year students of the Medicine degree (360 ETCS) at the University of San Pablo CEU (USP-CEU, Spain) during an Eramus+ mobility grant for academics in April 2017. The curriculum of this programme can

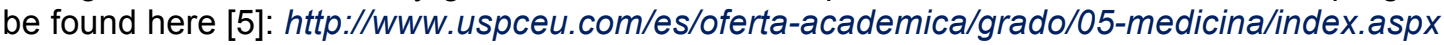

The training was prepared and delivered by a DMU academic to six year students $(n=100)$. As previously described by our group, Erasmus teaching staff mobility has been reported as a relevant tool to improve internationalisation and in the development of teaching methods and as a resource to strengthen curricula development [6]. We have used this staff mobility grant to determine the effectiveness of our training in a human health degree programme in a university from another European country.

The two hour training provided consisted of developing a complete intervention programme to deal with an outbreak of Crimean-Congo haemorrhagic fever (CCFH) virus following the steps of evidencebased public health. CCFH is a haemorrhagic fever virus causing devastating disease symptoms that result in intense and prolonged suffering in humans and has become an increasing global health concern [7]. The specialised training consisted of two teaching approaches: one mainly theoretical and the other predominantly practical. The theoretical part was very short as final year medical students have a deep understanding in infectious diseases and global public health (the syllabus of their programme are accessible through the USP-CEU website [5]). Students were debriefed about the Public Health England response at Sierra Leone to stop the Ebola outbreak described previously so they could learnt an understanding of an appropriate public health response to face and control an epidemic. Comprehensive information about the CCHF virus was provided including its life cycle, routes of infection and treatment. The practical part, consisted of the development of an intervention programme, was developed following previous experiences in developing novel training and adopting different pedagogies as highlighted above. Students were divided in small groups of 4 or 5 members and were asked to design an appropriate intervention programme for preventing an outbreak of infection due to CCHF virus in Europe. Students groups were encouraged to follow the six-steps approach described by Brownson et al. (1999) [8] to develop an appropriate intervention programme through performing a more analytic decision making of evidence-based public health. To overcome the time constraints of this workshop ( $2 \mathrm{~h}$ length) and to facilitate scientific literature search and information organisation, comprehensive information in the form of scientific papers and related information was provided at least one week before the session so students could analyse the evidence to develop and prioritize programme options. We also modified the pedagogy approach "peer teaching" described by Benè KL. and Bergus G. (2014) [9] by simplifying it to one hour session in which groups presented their results/interventions. During the discussion of the different groups, active participation and reasoning was sought from the students by formulating questions and analysis, and an understanding of each case study. This approach has been successful to provide students with the skills to tailor an appropriate intervention programme to protect human health in the aftermath of an outbreak. Moreover, it has been successful to clarify erroneous knowledge or misinformation.

To meet our objectives, comprehensive feedback was collected using the same validated feedbackquestionnaires developed by our team and used with DMU students. Peña-Fernández et al. (2015) [10] have described that questionnaires can measure the degree of satisfaction of the teaching and learning processes. This questionnaire contains different questions using the Likert scale (strongly disagree, disagree, neither agree nor disagree, agree, strongly agree) and open-questions (freeresponse). Ethical approval was provided by the Research Ethics Committee at DMU (Ref. 1729) and from the Ethics Committee at the USP-CEU (Ref. 143/17/01). 


\section{RESULTS}

The specialised training was overwhelming well-received by USP-CEU Medicine students, as evidenced by their favourable evaluation. The specific questionnaire used has shown high levels of engagement and satisfaction [100\% (31.2\% agreed; $68.8 \%$ strongly agreed)] with the USP-CEU medical students (Figure 1).
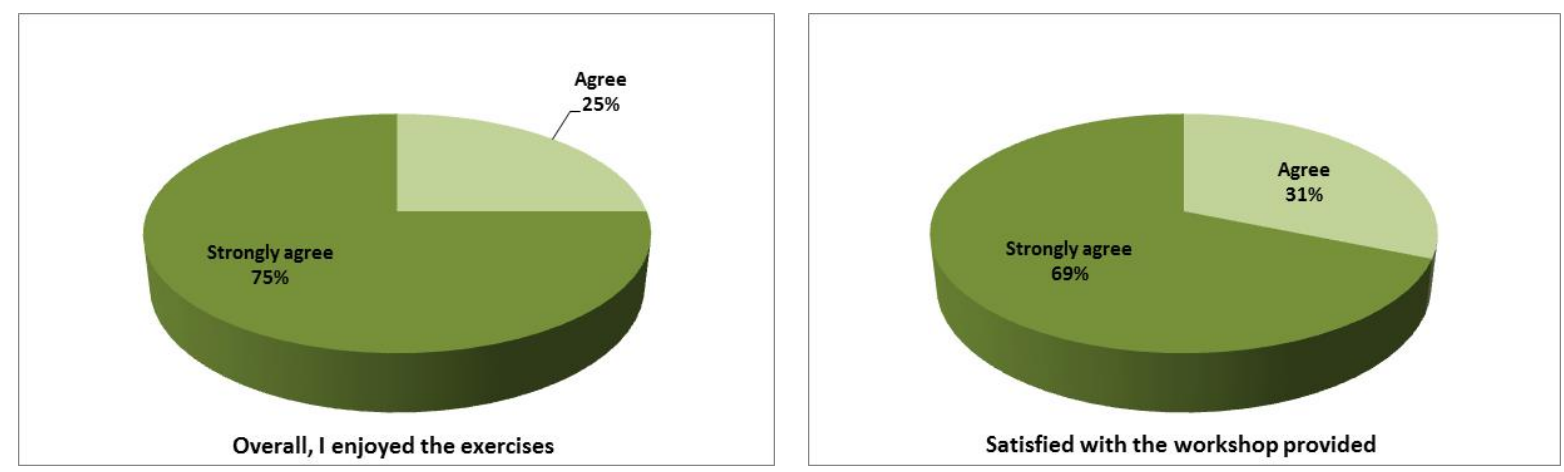

Figure 1. Student enjoyment and satisfaction (\%). Absence of a Likert category indicates no responses for that category.

Despite its short duration, this training would be successful in providing medical students with the necessary skills to respond to a biological event. Thus, $100 \%$ (31.2\% agreed; $68.8 \%$ strongly agreed) of these students reported that they learnt how to establish some public health interventions to protect humans in the aftermath of an outbreak of infection (Figure 2). Figures 3 and 4 shown participants opinion on their acquisition of knowledge on public health prevention and preparedness $(37.5 \%$ agreed; 62.5 strongly agreed) and how to investigate an outbreak of infection or pandemic.

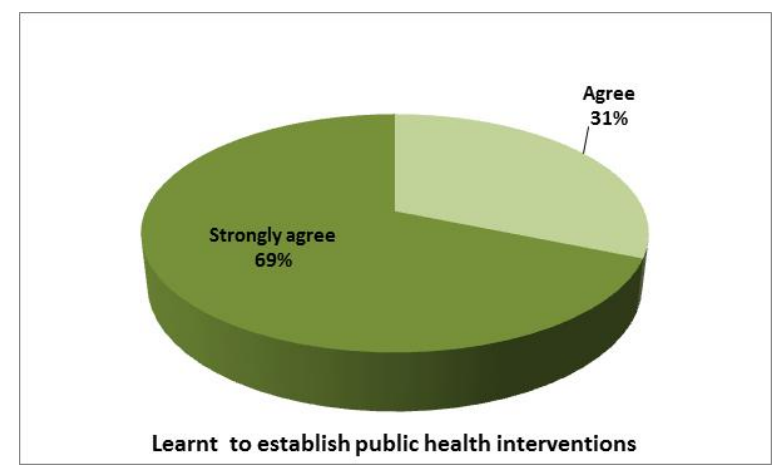

Figure 2. Student's learning on stablish interventions (\%). Absence of a Likert category indicates no responses for that category.

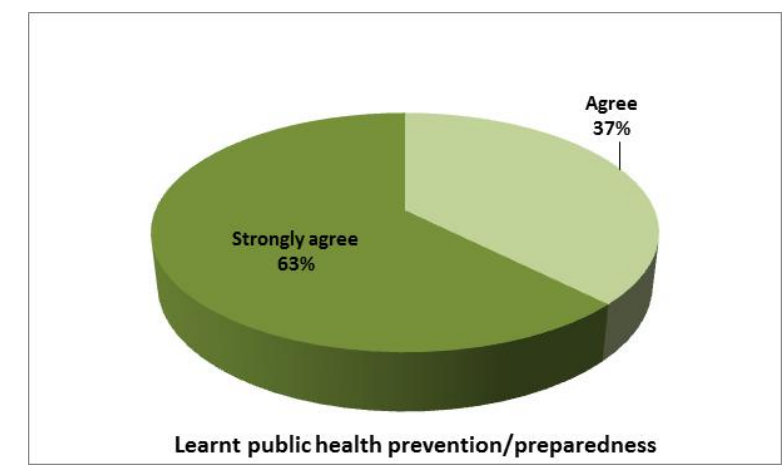

Figure 3. Student's learning on preparedness (\%). Absence of a Likert category indicates no responses for that category.

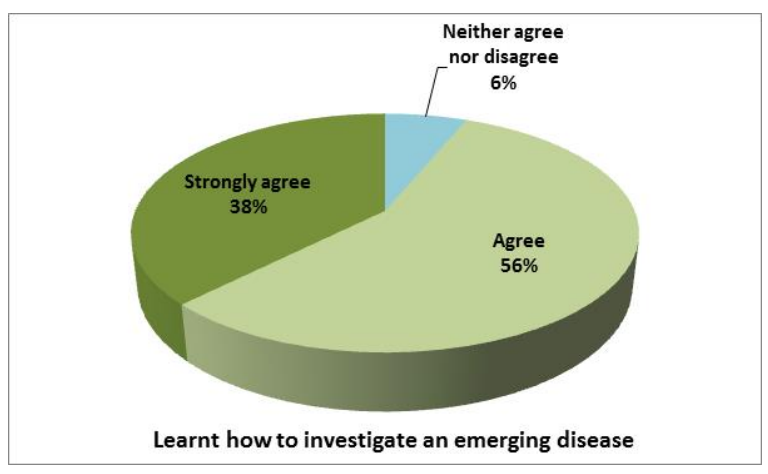

Figure 4. Student's learning on investigating an outbreak (\%).

Absence of a Likert category indicates no responses for that category. 
In relation to the content and duration of the specialised training, all participants have highlighted high levels of agreement with the relevance of the training to their medical programme (Figure 5) and with the appropriateness of the duration of the training delivered (Figure 6).

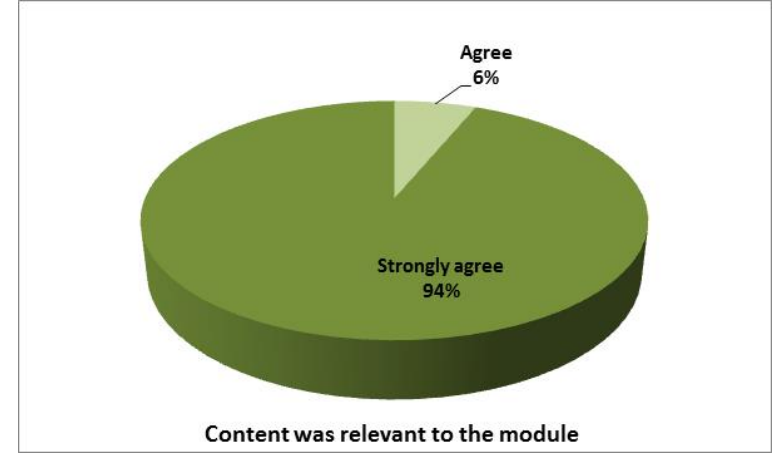

Figure 5. Student's opinion on the content of the training (\%). Absence of a Likert category indicates no responses for that category.

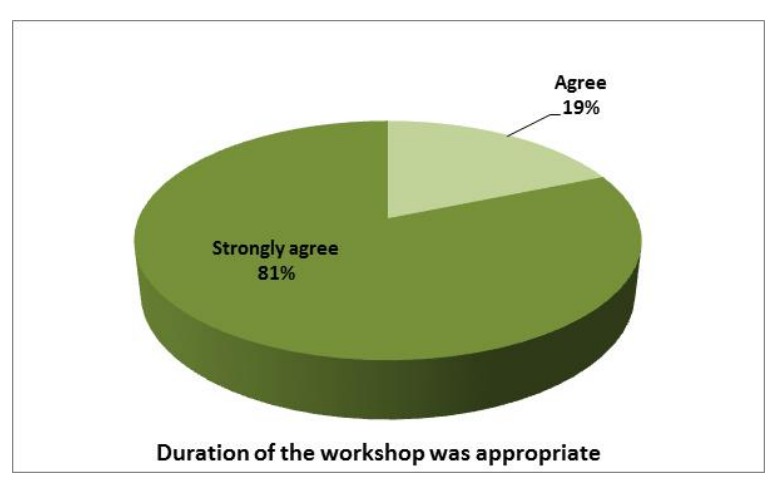

Figure 6. Student's opinion on the duration of the training (\%). Absence of a Likert category indicates no responses for that category.

\section{CONCLUSIONS}

We could indicate that, after careful evaluation of the preliminary data gathered so far, the specialised training develop would be effective on teaching basic medical response to protect public health to medical degrees. Moreover, the training would be also effective in non-English EU universities after appropriate tackling to adapt the public health responses to the characteristics of each country. Finally, the Erasmus+ mobility grant for academics has been shown to be a relevant tool and resource to strengthen curricula development and validation in higher education.

\section{ACKNOWLEDGEMENTS}

The authors would like to thank the Erasmus+ staff mobility funds granted (2016-17) to Dr. PeñaFernández.

\section{REFERENCES}

[1] Peña-Fernández A., Escalera Izquierdo B., Peña MA. Evaluating basic training for prevention and response to biological incidents. In: Research in university teaching. Designing the future based on educational innovation. Roig-Vila, Rosabel (ed.). Barcelona: Octaedro, 2017; pp. 358366. ISBN 978-84-9921-935-6.

[2] Brown N., Crawford I., Carley S., Mackway-Jones K. A Delphi-based consensus study into planning for biological incidents. Journal of Public Health (Oxf) 2006; 28(3):238-41.

[3] Peña-Fernández A., Choi EML. Novel methods of teaching evidence-based medicine and public health: experience from the field during the Ebola outbreak. ICERI2016 Proceedings; pp. 43274335.

[4] Peña-Fernández A., Dunford LJ., Haris PI., Lobo-Bedmar MC., Peña MA. Harmonising the training of students within the EU to implement intervention programmes to protect the public in the aftermath of a HazMat incident. ICERI2016 Proceedings; pp. 3559-3565.

[5] Medicine degree website. Available at the USP-CEU website: $h t t p: / / w w w . u s p c e u . c o m / e s / o f e r t a-$ academica/grado/05-medicina/index.aspx [accessed 25/01/2018]

[6] Peña-Fernández A., Peña MA., Ollero MD., Hurtado C., Fenoy S. Environmental recovery training for biological incidents: impressions from pharmacy students. EduLearn Proceedings 2017; 5080-5085. ISBN: 978-84-697-3777-4.

[7] Negredo A., de la Calle-Prieto F., Palencia-Herrejón E., Mora-Rillo M., Astray-Mochales J., Sánchez-Seco MP., Bermejo Lopez E., Menárguez J., Fernández-Cruz A., etc. Autochthonous Crimean-Congo Hemorrhagic Fever in Spain. N Engl J Med. 2017; 377(2):154-161. 
[8] Brownson RC, Gurney JG, Land GH. Evidence-based decision making in public health. J Public Health Manag Pract 1999; 5(5):86-97.

[9] Benè KL. and Bergus G. When learners become teachers: a review of peer teaching in medical student education. Fam Med 2014; 46(10):783-7.

[10] Peña-Fernández A., González-Muñoz MJ., Peña MA. Designing training for teaching environmental toxicology to specialized pharmacists. Currents in Pharmacy Teaching and Learning 2015; 7:864-868. 